North Carolina (under Busse), in Paris (under Bourlière), and in Liverpool (under Heron). The first three are multidisciplinary, including clinicians, physiologists and psychologists, and are set up on a long-term basis which permits and encourages the planning of repeated studies of the same individuals, but their subject populations are unbalanced and rather highly selected. The Liverpool work (although under Medical Research Council auspices) is almost entirely psychological, but has been based on what appears to be the most satisfactory body of subjects yet assembled for work on human aging. It is, however, not established on a permanent basis, thus making it difficult to envisage repeated studies of the same individuals, and the lack of clinical and physiological elements combines with an occupational orientation to reduce its potential for more fundamental work. It will therefore be seen that nowhere in the world is there anything resembling a satisfactorily co-ordinated attack on the interrelated processes of change in the adult life-span with which gerontology should be mainly concerned. To anyone wishing to see our limited resources of research funds and man-power applied strategically to this area of interest, these beautifully produced volumes are to a great extent but evidence of under-employed talent and a solid challenge to the vision of research administrators.

Alastair Heron

\section{TWO CHEERS FOR THE ORGANIZER}

\section{Primary Embryonic Induction}

By Lauri Saxen and Prof. Sulo Toivonen. (Scientific Monographs in Experimental Biology.) Pp. xi $+271+20$ plates. (London: Logos Press, Ltd., in association with Elek Books, Ltd. Distributed by Academic Press, Inc. (London), Ltd., 1962.) $50 \mathrm{~s}$.

NE of the more simple-minded theses about the scientific method is that if one wishes to understand a phenomenon, the first step must be to discover some method of controlling it. On these grounds, it has long been generally admitted that the discovery of embryonic induction by Spemann in the years around 1920 was a landmark in the history of the causal analysis of development. However, as is well known, 'the organizer story' quite soon found itself in deep water, in which any line of thought which might hope to get down to solid bed-rock would have to be able to penetrate some of the profoundest questions in the whole of biology. Most of the authors who had started with the biochemical approach, and found themselves gazing down into these impenetrable depths, thought discretion the better part of valour and turned their attention to other possibly more manageable problems. Fortunately enough, however, a new echelon of bolder spirits took over, and in the late 1940's and 1950's the organizer problem has seen a new lease of life.

The book under review has been written by the two Finnish authors who have been the centre of one of the most active schools of research in recent years. Toivonen, around 1940, was one of the first to demonstrate that certain tissues from adult vertebrates, if inserted into an early embryo, could not only control the development of the surrounding tissues so that they developed into some highly differentiated form, such as nerve, muscle, kidney, etc., but also could rather specifically induce the appearance of particular segments of the embryonic body, such as the fore-brain with its accompanying nose and eyes. or more posterior parts of the brain together with the ears, or the spinal cord surrounded by the somites and underlain by the notochord. He, and a fow other workers, have followed this up by chemical analysis. They have tried, with considerable success, to isolate the chemical substances responsible for switching the development of indifferent but competent embryonic tissues into various different pathways which lead to these complex late embryonic structures. Everyone interested in the problem of embryonic differentiation, and nowadays that includes not only embryologists in the strict sense but also, it is gratifying to note, many physiological geneticists and molecular biologists, must take into very serious consideration the facts which Saxén and Toivonen relate. We owe them a great debt for bringing together this scattered material into a single coherent account, with an extensive, though not exhaustive, bibliography.

The book is perhaps weakest on the theoretical side. There is, indeed, a considerable discussion of the more immediate theoretical issues. Are there only two, or more, classes of these adult ('heterologous') inducers? Is there only one substance in each class? Are these substances proteins (as seems probable) or nucleic acids? Do they induce organ-systems (fore-brain, spinal cord, or the like) or mixtures of tissues such as nervous tissue and mesoderm, which later re-arrange themselves into organs? On such points the authors show themselves critical and well balanced. But behind these issues lie other more profound ones which must be grappled with before the subject can be clearly formulated. What, for example, is implied by the suggestion that the initial products of the induction are mere masses of tissue, which then arrange or, as I prefer to say, 'individuate' themselves into organs? More fundamental still is the question whether the substances act 'directly', or 'indirectly' by relessing other compounds already present in the reacting cells. But what, in the last analysis, could we mean by a 'direct' action? I cannot see that any clear connotation can be attached to the phrase except in terms of a control exerted over the basic protein-synthesizing mechanisms of the reacting cells: and that involves essentially a consideration of their genes. It is, in my opinion, only when 'the organizer' is seen as part of the developmental physiology of the genetic system that one can ask the right questions about it. Saxen and Toivonen's book is most welcome and valuable; but it would have been even more illuminating if they had pushed their theoretical analysis down to this level. $\quad$ C. H. WADDINGTON

\section{BIOCHEMISTRY OF CANCER}

\section{Chemical Carcinogenesis}

By Dr. David B. Clayson. Pp. viii +567 . (London: J. and A. Churchill, Ltd., 1962.) $72 s$.

EADERS of scientific books often find difficulty in knowing for whom the books were intended. Dr. Clayson, however, says that he has in mind the needs of the graduate who has chosen to enter the field of cancer research; he hopes that it will be useful to research chemists and medical officers who are responsible for "the public health which is menaced by some of our technological advances".

The book in general seems admirably suited for people entering or even established in cancer research. Since the Biochemistry of Cancer by the late Dr. J. Greenstein became out of date, a modern equivalent has been needed. Even in 1954, when the second edition of Biochemistry of Cancer was written, it was something of a tour de force for one writer to cover the whole field. Dr. Clayson has provided a work which deals admirably with the induction of cancer by chemical substances. It is to be hoped that other authors will write equally good text-books on the chemotherapy of cancer, and on the chemistry and biochemistry of tumours.

Dr. Clayson deals with the subject under four main headings, including causation of cancer in man, the experimental determination of carcinogenic activity, 